Article

\title{
Iterative Method for Determining the Values of the Susceptances of a Balancing Capacitive Compensator
}

\author{
Adrian Pană, Alexandru Băloi and Florin Molnar-Matei *iD \\ Electrical Power Engineering Department, Politehnica University of Timișoara, 300006 Timișoara, Romania; \\ adrian.pana@upt.ro (A.P.); alexandru.baloi@upt.ro (A.B.) \\ * Correspondence: florin.molnar@upt.ro; Tel.: +40-256-403-428
}

Received: 17 September 2018; Accepted: 9 October 2018; Published: 12 October 2018

\begin{abstract}
To increase the electrical power quality, in the last decades, an intense development in the last decades of high-performance equipment built as advanced power electronics applications, such as the compensators from Switching Power Converter category, has taken place. For all that, Reactive Power Compensators (RPC) based on passive circuit elements, such as Static var Compensators (SVCs), still occupy a wide range of applications in customer and installations of the distribution system installations. The functions of power factor (PF) improvement and load balancing in a three-phase distribution network can be achieved with an unbalanced SVC, known as the Adaptive Balancing Reactive Compensator (ABRC). Presenting first the mathematical model of the initial sizing and the working mechanism of a Balancing Reactive Compensator (BRC) for a three-phase four-wire network, this article develops a compensator resizing algorithm through an iterative change of the initial sizing to transform the compensator into a Balancing Capacitive Compensator (BCC), which keeps the same functions. By using two computational and modeling software tools, a case study on the application of the method was carried out, demonstrating the availability of the sizing problem solution and validating the unbalanced capacitive compensation as an efficient way to PF improving and load balancing in a PCC (Point of Common Coupling).
\end{abstract}

Keywords: electrical power quality; reactive power compensator; Static var Compensator; adaptive balancing reactive compensator; balancing capacitive compensator; symmetrical component method

\section{Introduction}

Excessive reactive power load and three-phase voltage set asymmetry are two of the most important problems to be solved to ensure a high level of power quality in a PCC [1-3].

The most known means of mitigating/eliminating the three-phase network load unbalances are reactive power compensators (RPCs) containing passive circuit elements [4-28]. These have been developed especially in the last 3-4 decades, starting from the Steinmetz's balancing scheme, conceived over 100 years ago [4]. To be used efficiently for variable loads, PRCs have been designed to allow the adjustment of equivalent compensator circuit parameter values, thus obtaining static reactive power compensators (SVCs) [17-23].

Using units type Thyristor Controlled Reactor (TCR) and Thyristor Switched Capacitor (TSC), SVCs allow switching and parameter setting, respectively, of reactive passive circuit elements [5-8,12-15]. The most efficient applications of SVCs, for which they have proved to be fast and accurate enough, are intended for PF correction, load balancing, voltage regulation, and flicker mitigation [22].

At present, the second-generation of static compensators, type SPC, is being developed, which is based on high-power switching elements: Insulated Gate Bipolar Transistors (IGBT) or Thyristor Integrated Gate Commutated Thyristors (IGCT), belonging to the so-called Solid-State Devices (SSD) [29-34]. Found 
in wide variety, the compensators type Switching Power Converter (SPC) or Switching Compensator (SC) [29-44] are also part of the Custom Power Devices (CPD) category [44-49].

From the SPC category, the most common are Distribution Static Synchronous Compensator (D-STATCOM) [31,42,50,51], Dynamic Voltage Restorer (DVR) [31,34,35,44,52,53], and Unified Power Quality Conditioner (UPQC) $[41,43,46,47,54]$. Their basic component is a Voltage Source Inverter (VSI) $[40,48,49]$.

The accelerated evolution of technologies has made SPC equipment technically superior; the main arguments in this respect being: it allows for a more accurate adjustment, has a quicker response, is more compact and therefore occupies smaller spaces and is quieter. In addition, since it includes few passive circuit elements, SPC results in less active energy losses and thus has a higher energy efficiency.

However, for many applications of Electric Power Distribution System, including PF improvement and load balancing, SVCs are still preferred by users to SPC due to 30-35\% lower costs [55].

It is known that three-phase active and reactive inductive unbalanced loads can be balanced by unbalanced capacitance compensation [25-28]. The results of the theoretical and experimental studies obtained by the authors of this article make them believe that an SVC built as an Adaptive Balancing Capacitive Compensator (ABCC) based on Thyristor Switched Single Phase Capacitor (TSSPC) banks or Contactor Switched Single Phase Capacitor (CSSPC) banks can be the optimal solution for many applications, in both consumer and electricity distribution operator installations [26,28].

This article continues the subject of a previously published article [56], bringing a new solution to the same problem: sizing a BCC for PF improving and load balancing in a three-phase four-wire distribution network. First, the article briefly summarizes the mathematical model used to understand the operating of a Balancing Reactive Compensator (BRC), complemented by a new set of relationships to calculate the susceptances of the BRC structure, which are the basis for the new sizing method. Specifically, these susceptances are written according to symmetrical components of the load currents that they compensate. By iterative modification of the weights of these components, negative or zero values can be obtained for all susceptances, so BRC turns into a complete or incomplete BCC. A case study, performed using two software tools, confirms the mathematical model and validates unbalanced capacitive compensation as an efficient way for PF improving and load balancing.

\section{New Equations for Initial Sizing of a BRC}

As presented in [56], the mathematical model is developed by applying the symmetrical components method. For a three-phase four-wire network, both the positive sequence reactive current and the negative and zero-sequence currents of unbalanced loads can be eliminated by compensation using a Balancing Reactive Compensator containing only reactive circuit elements (coils and capacitors). Such a compensator must contain a three-phase circuit in Yn connection to compensate the zero sequence component and a three-phase circuit in $\Delta$ connection to compensate the negative sequences of load currents [6,8,14] (Figure 1). 


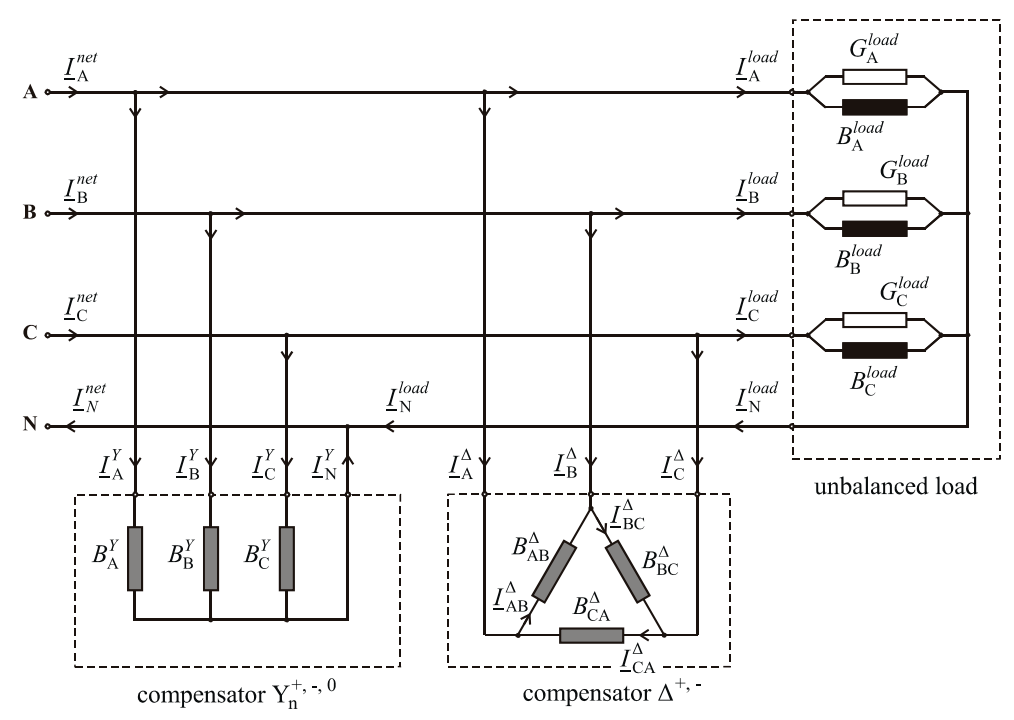

Figure 1. The BRC, in a three-phase four-wire network.

The compensation of the reactive components of the load positive sequence currents is also possible. Thereby the load-compensator assembly is seen from the network as a perfectly balanced equivalent active $[15,25,27]$.

The calculation of the values of the six susceptances from the compensator structure is done based on analytical expressions determined by cancellation of the symmetrical components with negative effects from the phase currents of the load-compensator assembly (absorbed in the PCC): the imaginary (reactive) component of the positive sequence current, and the real and imaginary components of the negative and zero sequence components $[10,14,27,56]$ :

$$
\operatorname{Im}\left(\underline{I}_{n e t}^{+}\right)=0, \operatorname{Re}\left(\underline{I}_{n e t}^{-}\right)=0, \operatorname{Im}\left(\underline{I}_{n e t}^{-}\right)=0, \operatorname{Re}\left(\underline{I}_{n e t}^{0}\right)=0, \operatorname{Im}\left(\underline{I}_{n e t}^{0}\right)=0
$$

in which

$$
\begin{aligned}
& \underline{I}_{\text {net }}^{+}=\underline{I}_{\text {load }}^{+}+\underline{I}_{Y}^{+}+\underline{I}_{\Delta}^{+} \\
& \underline{I}_{\text {net }}^{+}=\underline{I}_{\text {load }}^{-}+\underline{I}_{Y}^{-}+\underline{I}_{\Delta}^{-} \\
& \underline{I}_{\text {net }}^{0}=\underline{I}_{\text {load }}^{0}+\underline{I}_{Y}^{0}+\underline{I}_{\Delta}^{0}
\end{aligned}
$$

The determination of the six susceptances is preceded by the determination of the rms values of the currents flowing through them, hereinafter referred to as compensation currents. For this purpose, Equation (1) is completed with a sixth equation, to simplify the mathematical model and understand the load balancing mechanism by reactive compensation [10,27]:

$$
I_{A B}^{\Delta}+I_{B C}^{\Delta}+I_{C A}^{\Delta}=0
$$

Analytical solving of the equation system formed by Equations (1) and (3) leads to solutions that express the compensation currents depending on the real and imaginary components of the load sequence currents:

$$
\begin{gathered}
I_{A}^{Y}=\operatorname{Im}\left(\underline{I}_{\text {load }}^{+}\right)+2 \operatorname{Im}\left(\underline{I}_{\text {load }}^{0}\right) \\
I_{B}^{Y}=\operatorname{Im}\left(\underline{I}_{\text {load }}^{+}\right)+\sqrt{3} \operatorname{Re}\left(\underline{I}_{\text {load }}^{0}\right)-\operatorname{Im}\left(\underline{I}_{\text {load }}^{0}\right) \\
I_{C}^{Y}=\operatorname{Im}\left(\underline{I}_{\text {load }}^{+}\right)-\sqrt{3} \operatorname{Re}\left(\underline{I}_{\text {load }}^{0}\right)-\operatorname{Im}\left(\underline{I}_{\text {load }}^{0}\right)
\end{gathered}
$$




$$
\begin{gathered}
I_{A B}^{\Delta}=-\operatorname{Re}\left(\underline{I}_{\text {load }}^{-}\right)+\frac{1}{\sqrt{3}} \operatorname{Im}\left(\underline{I}_{\text {load }}^{-}\right)-\operatorname{Re}\left(\underline{I}_{\text {load }}^{0}\right)-\frac{1}{\sqrt{3}} \operatorname{Im}\left(\underline{I}_{\text {load }}^{0}\right) \\
I_{B C}^{\Delta}=-\frac{2}{\sqrt{3}} \operatorname{Im}\left(\underline{I}_{\text {load }}^{-}\right)+\frac{2}{\sqrt{3}} \operatorname{Im}\left(\underline{I}_{\text {load }}^{0}\right) \\
I_{C A}^{\Delta}=\operatorname{Re}\left(\underline{I}_{\text {load }}^{-}\right)+\frac{1}{\sqrt{3}} \operatorname{Im}\left(\underline{I}_{\text {load }}^{-}\right)+\operatorname{Re}\left(\underline{I}_{\text {load }}^{0}\right)-\frac{1}{\sqrt{3}} \operatorname{Im}\left(\underline{I}_{\text {load }}^{0}\right)
\end{gathered}
$$

The values of the compensation currents allow the quickly determination of the susceptances from the structure of the two compensators:

$$
\begin{gathered}
B_{A}^{Y}=\frac{1}{U} I_{A}^{Y}, \quad B_{B}^{Y}=\frac{1}{U} I_{B}^{Y}, \quad B_{C}^{Y}=\frac{1}{U} I_{C}^{Y} \\
B_{A B}^{\Delta}=\frac{1}{\sqrt{3} U} I_{A B}^{\Delta}, \quad B_{B C}^{\Delta}=\frac{1}{\sqrt{3} U} I_{B C}^{\Delta}, \quad B_{C A}^{\Delta}=\frac{1}{\sqrt{3} U} I_{C A}^{\Delta}
\end{gathered}
$$

For the six compensation currents and therefore for the corresponding susceptances, negative or positive values result, depending on the nature and load unbalance level. For the $\Delta$ compensator, it is observed that the algebraic sum of the values of the three compensation currents, thus of the three susceptances, is null, according to the condition in Equation (5), so some will be positive and some negative. As a result, at least one inductive susceptance (single-phase coil) and at least one capacitive susceptance (single-phase capacitor bank) will be included in the structure of the $\Delta$ compensator.

The analytical form of the compensation currents in Equations (4) and (5) allows quickly determining the expression for the currents on the phases of the two compensators [27]:

$$
\begin{gathered}
\underline{I}_{A}^{Y}=\left[-j \operatorname{Im}\left(\underline{I}_{\text {load }}^{+}\right)\right]+\left[\operatorname{Re}\left(\underline{I}_{\text {load }}^{0}\right)-j \operatorname{Im}\left(\underline{I}_{\text {load }}^{0}\right)\right]-\underline{I}_{\text {load }}^{0} \\
\underline{I}_{B}^{Y}=a^{2}\left[-j \operatorname{Im}\left(\underline{I}_{\text {load }}^{+}\right)\right]+a\left[\operatorname{Re}\left(\underline{I}_{\text {load }}^{0}\right)-j \operatorname{Im}\left(\underline{I}_{\text {load }}^{0}\right)\right]-\underline{I}_{\text {load }}^{0} \\
\underline{I}_{C}^{Y}=a\left[-j \operatorname{Im}\left(\underline{I}_{\text {load }}^{+}\right)\right]+a^{2}\left[\operatorname{Re}\left(\underline{I}_{\text {load }}^{0}\right)-j \operatorname{Im}\left(\underline{I}_{\text {load }}^{0}\right)\right]-\underline{I}_{\text {load }}^{0} \\
\underline{I}_{A}^{\Delta}=-\left(\underline{I}_{\text {load }}^{-}\right)-\left[\operatorname{Re}\left(\underline{I}_{\text {load }}^{0}\right)-j \operatorname{Im}\left(\underline{I}_{\text {load }}^{0}\right)\right] \\
\underline{I}_{B}^{\Delta}=-a\left(\underline{I}_{\text {load }}^{-}\right)-a\left[\operatorname{Re}\left(\underline{I}_{\text {load }}^{0}\right)-\operatorname{Im}\left(\underline{I}_{\text {load }}^{0}\right)\right] \\
\underline{I}_{C}^{\Delta}=-a^{2}\left(\underline{I}_{\text {load }}^{-}\right)-a^{2}\left[\operatorname{Re}\left(\underline{I}_{\text {load }}^{0}\right)-j \operatorname{Im}\left(\underline{I}_{\text {load }}^{0}\right)\right]
\end{gathered}
$$

The writing of the relations in Equations (8) and (9) was done by a coordinated grouping of the terms, allowing the explanation of the compensation mechanism. At the same time, the relations allow the sizing of the susceptances directly dependent only on the sequence components of the currents which they compensate.

According to the relations in Equation (8), each of the three phase currents on the Yn compensator can be decomposed into three components, each belonging to a three-phase currents set:

- $\quad$ one of positive sequence, which cancels (totally compensates) the imaginary (reactive) components of the positive sequence currents of the load;

- one of negative sequence, which cancels (totally compensates) a part of the negative sequence components on the $\Delta$ compensator phases; and

- one of zero sequence, which cancels (totally compensates) the zero sequence components of the load currents.

It is also observed that the current on the neutral conductor of the Yn compensator cancels (totally compensates) the current from the neutral conductor of the load, because:

$$
\underline{I}_{A}^{Y}+\underline{I}_{B}^{Y}+\underline{I}_{C}^{Y}=-3 \underline{I}_{\text {load }}^{0}=-\left(\underline{I}_{A}^{\text {load }}+\underline{I}_{B}^{\text {load }}+\underline{I}_{C}^{\text {load }}\right)
$$


According to the relations in Equation (9), each of the three currents on the $\Delta$ compensator phases can be decomposed into two components, each belonging to a set of three-phase negative sequence currents:

- a main one, which cancels (totally compensates) the negative sequence of the load currents; and

- a secondary one, which cancels (totally compensates) the negative sequence of the currents from the Yn compensator phases.

Thus, the $\Delta$ compensator intervenes only on the negative sequence currents flowing.

The fact that $\Delta$ compensator does not intervene on the zero sequence currents flow is also confirmed by the cancellation of the phasors sum of the currents on its phases:

$$
\underline{I}_{A}^{\Delta}+\underline{I}_{B}^{\Delta}+\underline{I}_{C}^{\Delta}=0
$$

This mathematical decomposition of currents on the phases of the two compensators, allows us to deduct the relations of sizing four fictitious compensators, denoted as follows:

- $Y^{+}$compensator, which compensates the imaginary (reactive) components of the load positive sequence currents;

- $\quad Y^{0,-}$ compensator, which compensates the zero sequence components of the load currents and the negative sequence components of the currents on the $\Delta_{2}^{-}$compensator phases;

- $\Delta_{1}^{-}$compensator, which compensates the negative sequence components of the load currents; and

- $\Delta_{2}^{-}$compensator, which compensates the negative sequence components of the currents on the $Y^{0,-}$ compensator phases.

The susceptances values of the four fictitious compensators structure can be determined by expressions that directly relate them only to the sequence components of the load currents the respective compensator compensates:

$$
\begin{gathered}
B_{A}^{Y+}=B_{B}^{Y+}=B_{C}^{Y+}=\frac{1}{U} \operatorname{Im}\left(\underline{I}_{\text {load }}^{+}\right) \\
B_{A}^{Y 0,-}=\frac{1}{U}\left[2 \operatorname{Im}\left(\underline{I}_{\text {load }}^{0}\right)\right] \\
B_{B}^{Y 0,-}=\frac{1}{U}\left[\sqrt{3} \operatorname{Re}\left(\underline{I}_{\text {load }}^{0}\right)-\operatorname{Im}\left(\underline{I}_{\text {load }}^{0}\right)\right] \\
B_{C}^{Y 0,-}=\frac{1}{U}\left[-\sqrt{3} \operatorname{Re}\left(\underline{I}_{\text {load }}^{0}\right)-\operatorname{Im}\left(\underline{I}_{\text {load }}^{0}\right)\right] \\
B_{A B}^{\Delta 1-}=\frac{1}{\sqrt{3} U}\left[-\operatorname{Re}\left(\underline{I}_{\text {load }}^{-}\right)+\frac{1}{\sqrt{3}} \operatorname{Im}\left(\underline{I}_{\text {load }}^{-}\right)\right] \\
B_{B C}^{\Delta 1-}=\frac{1}{\sqrt{3} U}\left[-\frac{2}{\sqrt{3}} \operatorname{Im}\left(\underline{I}_{\text {load }}^{-}\right)\right] \\
B_{C A}^{\Delta 1-}=\frac{1}{\sqrt{3} U}\left[\operatorname{Re}\left(\underline{I}_{\text {load }}^{-}\right)+\frac{1}{\sqrt{3}} \operatorname{Im}\left(\underline{I}_{\text {load }}^{-}\right)\right] \\
B_{A B}^{\Delta 2-}=\frac{1}{\sqrt{3} U}\left[-\operatorname{Re}\left(\underline{I}_{\text {load }}^{0}\right)-\frac{1}{\sqrt{3}} \operatorname{Im}\left(\underline{I}_{\text {load }}^{0}\right)\right] \\
B_{B C}^{\Delta 2-}=\frac{1}{\sqrt{3} U}\left[\frac{2}{\sqrt{3}} \operatorname{Im}\left(\underline{I}_{\text {load }}^{0}\right)\right] \\
B_{C A}^{\Delta 2-}=\frac{1}{\sqrt{3} U}\left[\operatorname{Re}\left(\underline{I}_{\text {load }}^{0}\right)-\frac{1}{\sqrt{3}} \operatorname{Im}\left(\underline{I}_{\text {load }}^{0}\right)\right]
\end{gathered}
$$

These fictitious compensators can have real correspondence, but their practical use is not of interest. Instead, the expressions for calculating their equivalent susceptances are of interest in the development of a resizing algorithm that changes the initial dimensioning to obtain real compensators containing 
only negative (capacitive) or null susceptances and fulfilling the same functions: PF improvement and load balancing in the PCC.

\section{Resizing the BRC for Converting It into a BCC}

The initial sizing criterion is useful in that it simplifies the mathematical model. At the same time, an easier understanding of the balancing mechanism.

The sixth sizing condition (Equation (3)) means that both the capacities and the inductances are included in the compensator's structure, which is not the best solution from the practical point of view. On the one hand, the presence of the high-power single-phase coils in the BRC structure leads to an increase in their cost and complicates the construction of an automatic control system requested in the case of variable loads (built, for example, by units type TCR). On the other hand, the allocation of all capacitive reactive power, required for capacitive compensation on the positive sequence, to the $\mathrm{Yn}$ compensator, leads to an irrational use of the capacitors.

As a result, idea to design a BRC that contains only capacitor banks appeared, which, in addition to eliminating the disadvantage presented above, would bring an important additional advantage. It can be more easily transformed into an $A B R C$ by using a simple automatic control system based on TSC. ABRC will therefore have the particular form of ABCC that will respond to the load variation by switching the steps of three single-phase capacitor banks.

This article proposes a method of sizing the six susceptances of the BRC that starts from the initial solution of the problem, presented above, and then operates an iterative change, by applying the principle of the capacitive reactive power transfer on the positive sequence from the $\mathrm{Yn}$ compensator to the $\Delta$ compensator. This transfer is done in such a way as to obtain for all the susceptances of the two compensators only negative or zero values, i.e. BRC is converted into a BCC.

In the case of common loads, by applying the initial sizing, the $\Delta$ compensator results with one or two inductive susceptances and the Yn compensator results only with capacitive susceptances.

By applying the new method, the capacitive reactive power corresponding to the positive sequence currents, resulting in the Yn compensator from the initial solution, is totally or partially transferred to the $\Delta$ compensator. The effect of compensation on the PF improvement and load balancing in the PCC depends on the value of this capacitive reactive power available for the transfer.

By appealing to the fictitious compensators, this transfer will be done from the $Y^{+}$compensator, as defined above, to a fifth fictitious balanced compensator, having $\Delta$ connection, introduced in the mathematically model, which will totally or partially take over the function of balanced capacitive compensation, meaning the PF improvement. This compensator, denoted $\Delta^{+}$, will contain three capacitive susceptances whose values are determined directly related to the imaginary (reactive) components of the positive sequence currents of the load, that is, the ones that it compensates:

$$
B_{A B}^{\Delta+}=B_{B C}^{\Delta+}=B_{C A}^{\Delta+}=k_{\Delta}^{+} \frac{1}{3 U} \operatorname{Im}\left(\underline{I}_{\text {load }}^{+}\right)
$$

The level at which the $\Delta+$ fictitious compensator will compensate the reactive components of the positive sequence currents of the load depends on the value of the weighting factor $k_{\Delta}^{+}$, positive, subunit $\left(0<k_{\Delta}^{+} \leq 1\right)$ and whose value is to be determined.

This weighting operation of the load sequence currents components, which intervene in the calculating expressions of the susceptances from the fictitious compensators structure, is also applied to the use of calculating relations for the susceptances of the other four fictitious compensators (Equations (11)-(15)). Weighting factors are positive and subunits, and are denoted as follows:

- $\quad k_{Y}^{+}$determines weighing of the $\operatorname{Im}\left(\underline{I}_{\text {load }}^{+}\right)$component to determining the values of $B_{A}^{Y+}, B_{B}^{Y+}$, snf $B_{C}^{Y+}$ susceptances.

- $\quad k_{\Delta}^{-}$determines weighing of the $\operatorname{Re}\left(\underline{I}_{I_{\text {load }}}^{-}\right)$and $\operatorname{Im}\left(\underline{I}_{\text {load }}^{-}\right)$components to determining the values of $B_{A B}^{\Delta 1-}, B_{B C}^{\Delta 1-}$, and $B_{C A}^{\Delta 1-}$ susceptances. 
- $\quad k_{Y, \Delta}^{0}$ determines weighing of the $\operatorname{Re}\left(\underline{I}_{\text {load }}^{0}\right)$ and $\operatorname{Im}\left(\underline{I}_{\text {load }}^{0}\right)$ components to determining the values of $B_{A B}^{\Delta 2-}, B_{B C}^{\Delta 2-}$, and $B_{C A}^{\Delta 2-}$, and $B_{A}^{Y 0,-}, B_{B}^{Y 0,-}$, and $B_{C}^{Y 0,-}$ susceptances, respectively.

It is obvious that the weighting factors $k_{\Delta}^{+}$and $k_{Y}^{+}$must fulfill the condition of avoiding the capacitive over-compensation on the positive sequence:

$$
0 \leq k_{\Delta}^{+}+k_{Y}^{+} \leq 1
$$

Thus, in compensating the imaginary component of the positive sequence current of the load, both the $Y^{+}$and the $\Delta^{+}$compensators participate. For $k_{\Delta}^{+}+k_{Y}^{+}=1$, the $Y^{+}$and $\Delta^{+}$compensators together carry out the total compensation of the reactive components of the positive sequence currents, so that $\cos \varphi^{+}=1$.

The allowable level of reactive power compensation on the positive sequence is denoted $k_{Q}^{+}=k_{\Delta}^{+}+k_{Y}^{+}$. It can be said that this level is distributed between the two fictitious compensators $\left(Y^{+}\right.$and $\left.\Delta^{+}\right)$by the coefficients $k_{Y}^{+}$and $k_{\Delta}^{+}$.

When $k_{\Delta}^{-}=1$, the $\Delta_{1}^{-}$compensator totally compensates the negative sequence components of the load currents.

For $k_{Y, \Delta}^{0}=1$, the $Y^{0,-}$ and $\Delta_{2}^{-}$compensators perform together the total compensation of the zero-sequence components of the load currents.

The problem solved by the method proposed in the present paper is to find those values of the weighting factors for which the values of the susceptances from the real compensators structure (Figure 2), obtained by connecting the fictitious compensators in parallel, result negative or null values (18) and (19).

$$
\begin{gathered}
B_{A}^{Y *}=k_{Y}^{+} B_{A}^{Y+}+k_{Y, \Delta}^{0} B_{A}^{Y 0,-} \leq 0 \\
B_{B}^{Y *}=k_{Y}^{+} B_{B}^{Y+}+k_{Y, \Delta}^{0} B_{B}^{Y 0,-} \leq 0 \\
B_{C}^{Y *}=k_{Y}^{+} B_{C}^{Y+}+k_{Y, \Delta}^{0} B_{C}^{Y 0,-} \leq 0 \\
B_{A B}^{\Delta *}=k_{\Delta}^{+} B_{A B}^{\Delta+}+k_{\Delta}^{-} B_{A B}^{\Delta 1-}+k_{Y, \Delta}^{0} B_{A B}^{\Delta 2-} \leq 0 \\
B_{B C}^{\Delta *}=k_{\Delta}^{+} B_{B C}^{\Delta+}+k_{\Delta}^{-} B_{B C}^{\Delta 1-}+k_{Y, \Delta}^{0} B_{B C}^{\Delta 2-} \leq 0 \\
B_{C A}^{\Delta *}=k_{\Delta}^{+} B_{C A}^{\Delta+}+k_{\Delta}^{-} B_{C A}^{\Delta 1-}+k_{Y, \Delta}^{0} B_{C A}^{\Delta 2-} \leq 0
\end{gathered}
$$

The method of solving the problem consists in the application of an iterative algorithm which, starting from the initial solution in Equations (8) and (9), determines the values of the weighting $k_{\Delta}^{+}, k_{Y}^{+}, k_{\Delta}^{-}$and $k_{Y, \Delta}^{0}$ that lead to a corrected solution, for which all the susceptances become negative (capacitive) or null (Equations (18) and (19)).

Weighting factors are actually the compensation levels of the positive, negative and zero sequence components of the load currents.

The algorithm can be implemented in the automatic control system of an ABCC built with TSCs, so that the four weighting factors become control variables for the automatic control system. Figure 3 shows the simplified logical schema associated with the implementation algorithm of the method. 

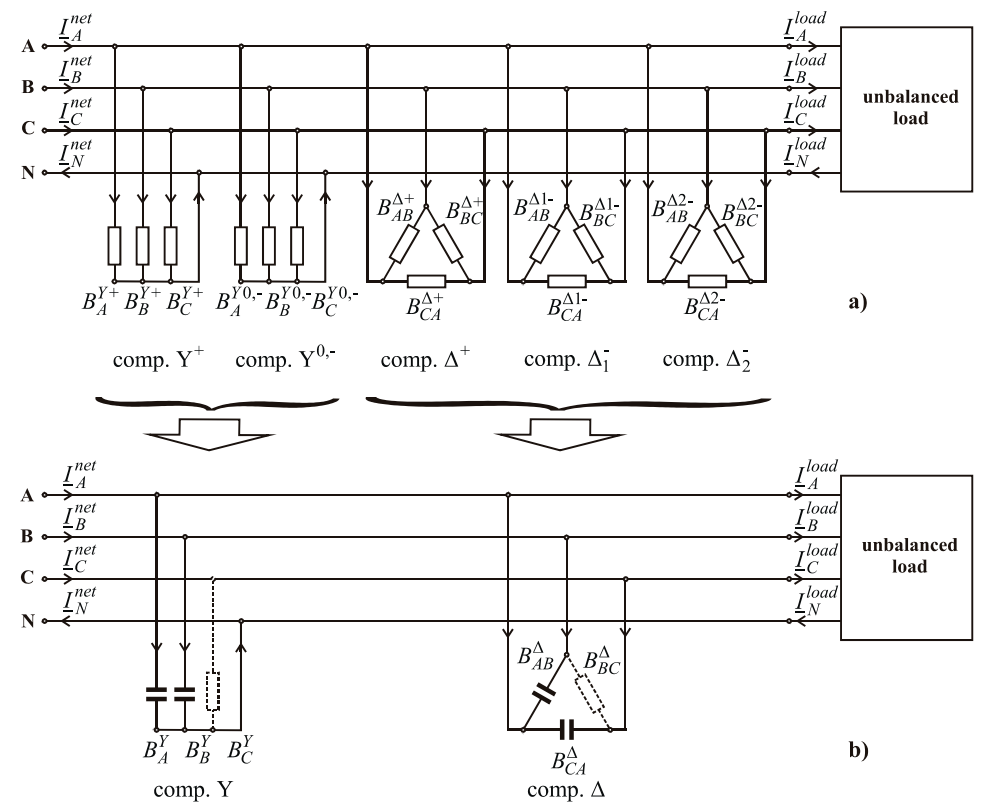

Figure 2. Electrical circuit of the five fictitious compensators (a) respectively of the two real compensators (b).

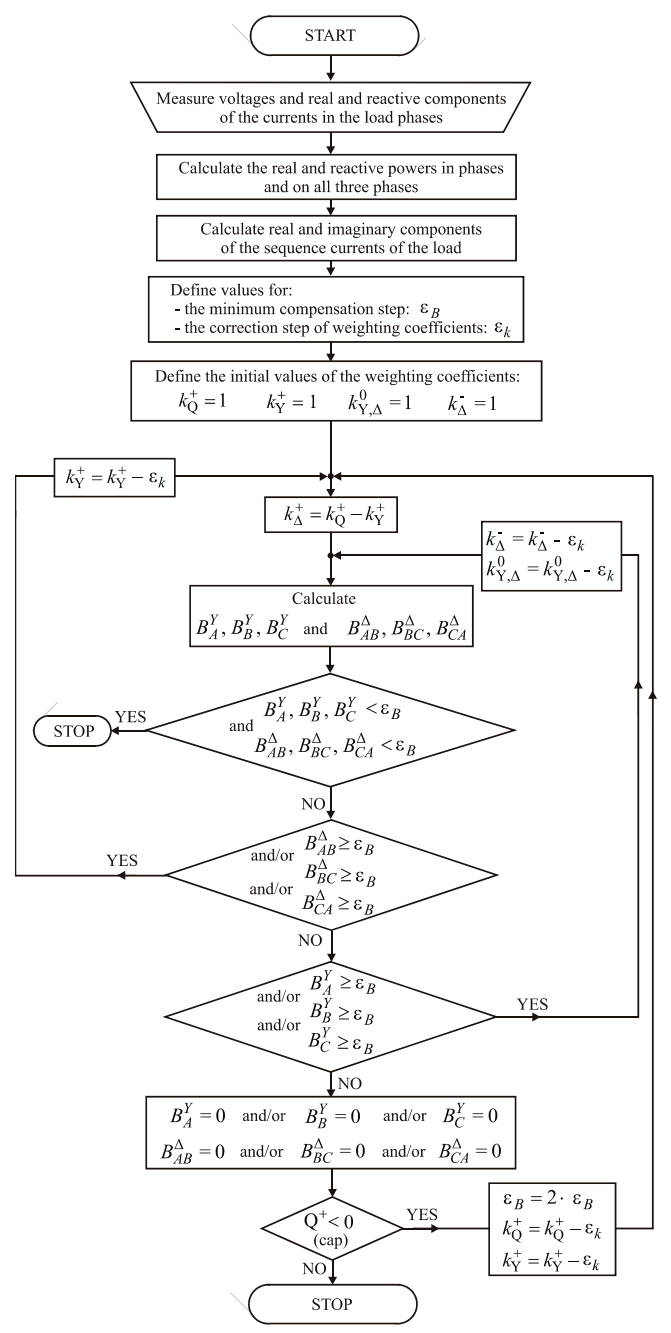

Figure 3. Simplified flowchart associated with the iterative method. 
Before the iterative calculation of the susceptances values begins, the value of another control value is determined: the maximum correction applied to the susceptances which result with positive values from the calculation and which are eliminated from the compensator circuits, denoted $\varepsilon_{B}$. It can be said that the value $-\varepsilon_{B}$ is the value of the minimum compensation step.

Then, the initial values of the compensation current weighting factors are estab lished, which will be subject of an iterative correction process. They are considered $k_{Q}^{+}=1$ and $k_{Y}^{+}=1$ (thus, $\left.k_{\Delta}^{+}=0\right), k_{Y, \Delta}^{0}=1$ and $k_{\Delta}^{-}=1$. With these values of weighting factors, the values for the six real susceptances are obtained; values correspond to the total compensation of the reactive power on the positive sequence and total load balancing, given by the initial sizing. Often, some real susceptances result positive, meaning inductive, which needs to be corrected. The correction is done by iteratively changing of the weighting factors values, thus the compensation currents.

First, the distribution of the compensation current on the positive sequence is changed between the two circuits Yn and $\Delta$, keeping the same value of $k_{Q}^{+}$and modifying the values of $k_{Y}^{+}$and $k_{\Delta}^{+}$in the sense of decreasing as much as possible the number and the value of the positive susceptances. Decreasing the value of positive susceptances below the $\varepsilon_{B}$ threshold leads to disconnection (opening) of the respective compensator branches. If this decrease is not possible only by decreasing the factors $k_{Y}^{+}$and $k_{\Delta}^{+}$, then the factors $k_{\Delta}^{-}$and $k_{Y, \Delta}^{0}$ are also reduced in successive steps. As the $k_{\Delta}^{-}$and $k_{Y, \Delta}^{0}$ factors are smaller, the balancing effect of the compensation is lower. The correction step of the weighting factor denoted $\varepsilon_{k}$ is also set before the iterative calculation begins.

Removing the remaining positive susceptances leads to capacitive over-compensation on the positive sequence. This is avoided by reducing the level of compensation on the positive sequence, thus by $k_{Q}^{+}$decreasing. However, decreasing the value of the $k_{Q}^{+}$factor is equivalent to $\cos \varphi^{+}$decrease, therefore this operation must be limited by the condition $\cos \varphi^{+} \geq \cos \varphi_{\text {min }}$. The iterative process of weighting factors correction resumes and continues until all the susceptances values result negative or null. At this time, the iterative calculation stops and the control system of the ABCC commands the connection/disconnection of the corresponding steps of the six single-phase capacitor banks.

For loads with a high level of unbalance, within the iterative calculation process, the value of the $\varepsilon_{B}$ threshold can also be increased.

The result of each adjustment cycle is a compromise between the two contradictory tendencies: the use of a compensation capacitive reactive power as high as possible to obtain a higher level of load balancing (negative and zero sequence compensation) and limitation of the compensation capacitive reactive power to avoid the capacitive over-compensation on the positive sequence.

In all practical situations, such an unbalanced capacitive compensator, in addition to $\mathrm{PF}$ improvement, determines also a higher or lower, sometimes total, mitigation of load unbalance, which always makes it more useful than a "classic" capacitive compensator, which does not have this additional function.

\section{Case Study}

To verify the mathematical model presented above, a case study was carried out, and the results are presented below. Two software tools were used: one for numerical study of the sizing and operation of a BRC (Mathcad) and the other for modeling and analysis of the operating conditions of the same BRC (MatLab-Simulink).

Both sizing versions described above are considered, the initial one, interesting by its effects on the compensation mechanism (BRC), and the version obtained by resizing, made up only by single phase capacitor banks (BCC).

The numerical results obtained using the Mathcad software tool, for sizing the compensator in the two versions, and afterwards the calculation results for currents and powers flowing on the phases of the load-compensator assembly are presented in Tables 1-4. For the currents, both phase and symmetrical components were used. 
Table 1. Unbalanced three-phase load-values valid for both compensators.

\begin{tabular}{|c|c|c|c|c|}
\hline $\begin{array}{l}\text { Equivalent } \\
\text { Parameters }\end{array}$ & Active Powers & Reactive Powers & Phase Currents & Sequence Currents \\
\hline $\begin{array}{c}R_{A}^{\text {load }}=39.45 \Omega \\
R_{B}^{\text {load }}=110.45 \Omega \\
R_{C}^{\text {load }}=69.03 \Omega \\
L_{A}^{\text {load }}=195.32 \mathrm{mH} \\
L_{B}^{\text {load }}=97.66 \mathrm{mH} \\
L_{C}^{\text {load }}=83.71 \mathrm{mH}\end{array}$ & $\begin{array}{c}P_{A}^{\text {load }}=1400 \mathrm{~W} \\
P_{B}^{\text {load }}=500 \mathrm{~W} \\
P_{C}^{\text {lood }}=800 \mathrm{~W} \\
P_{\text {tot }}^{\text {load }}=2700 \mathrm{~W} \\
P_{\text {av }}^{\text {load }}=900 \mathrm{~W} \\
-\end{array}$ & $\begin{array}{c}Q_{A}^{\text {load }}=900 \mathrm{var} \\
Q_{B}^{\text {load }}=1800 \mathrm{var} \\
Q_{C}^{\text {load }}=2100 \mathrm{var} \\
Q_{\text {tot }}^{\text {lood }}=4800 \mathrm{var} \\
Q_{a v}^{\text {lood }}=1600 \mathrm{var} \\
-\end{array}$ & $\begin{array}{c}\underline{I}_{A}^{\text {load }}=(5.957-j 3.83) \mathrm{A} \\
\underline{I}_{A}^{\text {load }}=7.082-32.74^{\circ} \mathrm{A} \\
\underline{I}_{B}^{\text {load }}=(-7.697+j 1.987) \mathrm{A} \\
\underline{I}_{B}^{\text {load }}=7.950 \frac{165.52^{\circ}}{} \mathrm{A} \\
\underline{I}_{C}^{\text {load }}=(6.037+j 7.416) \mathrm{A} \\
\underline{I}_{C}^{\text {load }}=9.563 \frac{150.85^{\circ}}{} \mathrm{A}\end{array}$ & $\begin{array}{c}\underline{I}_{\text {load }}^{+}=(3.83-j 6.809) \mathrm{A} \\
\underline{I}_{\text {load }}^{+}=7.812 \frac{-60.64^{\circ}}{} \mathrm{A} \\
\underline{I}_{\text {load }}^{-}=(0.695+j 1.121) \mathrm{A} \\
\underline{I}_{\text {load }}^{-}=1.319 / 58,19^{\circ} \\
\underline{I}_{\text {load }}=(1.432+j 1.858) \mathrm{A} \\
\underline{I}_{\text {load }}^{0}=2.346 \frac{152.37^{\circ}}{} \mathrm{A}\end{array}$ \\
\hline
\end{tabular}

Table 2. The unbalanced compensator-initial sizing (BRC).

\begin{tabular}{|c|c|c|c|c|c|}
\hline Compo-nent & $\begin{array}{l}\text { Equivalent } \\
\text { Parameters }\end{array}$ & Active Powers & Reactive Powers & Phase Currents & Sequence Currents \\
\hline Yn & $\begin{array}{c}C_{A}^{Y}=41.892 u \mathrm{~F} \\
C_{B}^{Y}=83.783 u \mathrm{~F} \\
C_{C}^{Y}=150.991 u \mathrm{~F} \\
- \\
- \\
-\end{array}$ & $\begin{aligned} P_{A}^{Y} & =0 \mathrm{~W} \\
P_{B}^{Y} & =0 \mathrm{~W} \\
P_{C}^{Y} & =0 \mathrm{~W} \\
P_{t o t}^{Y} & =0 \mathrm{~W} \\
P_{a v}^{Y} & =0 \mathrm{~W} \\
& -\end{aligned}$ & $\begin{array}{c}Q_{A}^{Y}=-726.79 \mathrm{var} \\
Q_{B}^{Y}=-1453.59 \mathrm{var} \\
Q_{C}^{Y}=-2619.62 \mathrm{var} \\
Q_{t o t}^{Y}=-4800 \mathrm{var} \\
Q_{a v}^{Y}=-1600 \mathrm{var} \\
-\end{array}$ & $\begin{array}{c}\underline{I}_{A}^{Y}=(0+j 3.093) \mathrm{A} \\
\underline{I}_{A}^{Y}=3.093 \frac{/ 90^{\circ}}{\mathrm{A}} \\
\underline{I}_{B}^{Y}=(5.357-j 3.093) \mathrm{A} \\
\underline{I}_{B}^{Y}=6.185 \frac{-30^{\circ}}{\mathrm{A}} \mathrm{A} \\
\underline{I}_{C}^{Y}=(-9.654-j 5.574) \mathrm{A} \\
\underline{I}_{C}^{Y}=11.147 \frac{-150^{\circ}}{\mathrm{A}} \mathrm{A}\end{array}$ & $\begin{array}{c}\underline{I}_{Y}^{+}=(0+j 6.809) \mathrm{A} \\
\underline{I}_{Y}^{+}=6.809 \frac{/ 90^{\circ}}{} \mathrm{A} \\
\underline{I}_{Y}^{-}=(1.432-j 1.858) \mathrm{A} \\
\underline{I}_{Y}^{-}=2.346 \frac{/-52.37^{\circ}}{\mathrm{A}} \\
\underline{I}_{Y}^{0}=(-1.432-j 1.858) \mathrm{A} \\
\underline{I}_{Y}^{0}=2.346 \frac{1-127.63^{\circ}}{\mathrm{A}}\end{array}$ \\
\hline$\Delta$ & $\begin{aligned} C_{A B}^{\Delta}= & 19.967 u \mathrm{~F} \\
L_{B C}^{\Delta}= & 1522.36 \mathrm{H} \\
L_{C A}^{\Delta}= & 761.18 \mathrm{H} \\
& - \\
- & -\end{aligned}$ & $\begin{array}{c}P_{A}^{\Delta}=-500 \mathrm{~W} \\
P_{B}^{\Delta}=400 \mathrm{~W} \\
P_{C}^{\Delta}=100 \mathrm{~W} \\
P_{t o t}^{\Delta}=0 \mathrm{~W} \\
P_{a v}^{\Delta}=0 \mathrm{~W} \\
-\end{array}$ & $\begin{array}{c}Q_{A}^{\Delta}=-173.21 \mathrm{var} \\
Q_{B}^{\Delta}=-346.41 \mathrm{var} \\
Q_{C}^{\Delta}=519.62 \mathrm{var} \\
Q_{t o t}^{\Delta}=0 \mathrm{var} \\
Q_{a v}^{\Delta}=0 \mathrm{var} \\
-\end{array}$ & $\begin{array}{c}\underline{I}_{A}^{\Delta}=(-2.128+j 0.737) \mathrm{A} \\
\underline{I}_{A}^{\Delta}=2.252 \frac{160.89^{\circ}}{} \mathrm{A} \\
\underline{I}_{B}^{\Delta}=(0.426-j 2.211) \mathrm{A} \\
\underline{I}_{B}^{\Delta}=2.252 \frac{/-79.11^{\circ}}{A} \mathrm{~A} \\
\underline{I}_{C}^{\Delta}=(1.702+j 1.474) \mathrm{A} \\
\underline{I}_{C}^{\Delta}=2.252 \frac{/ 40.89^{\circ}}{} \mathrm{A}\end{array}$ & $\begin{array}{c}\underline{I}_{\Delta}^{+}=(0+j 0) \mathrm{A} \\
\underline{I}_{\Delta}^{+}=0 \frac{/ 0^{\circ}}{\mathrm{A}} \\
\underline{I}_{\Delta}^{-}=(-2.128+j 0.737) \mathrm{A} \\
\underline{I}_{\Delta}^{-}=2.252 \underline{/ 160.89^{\circ}} \mathrm{A} \\
\underline{I}_{\Delta}^{0}=(0+j 0) \mathrm{A} \\
\underline{I}_{\Delta}^{0}=0 \frac{/ 0^{\circ}}{} \mathrm{A}\end{array}$ \\
\hline
\end{tabular}

Table 3. The unbalanced compensator-resized (BCC).

\begin{tabular}{|c|c|c|c|c|c|}
\hline Compo-nent & $\begin{array}{l}\text { Equivalent } \\
\text { Parameters }\end{array}$ & Active Powers & Reactive Powers & Phase Currents & Sequence Currents \\
\hline$Y C_{B}^{Y}=41.89 u \mathrm{~F}$ & $\begin{aligned} C_{A}^{Y} & =0 u \mathrm{~F} \\
C_{B}^{Y}= & 41.89 u \mathrm{~F} \\
C_{C}^{Y}= & 109.1 u \mathrm{~F} \\
& - \\
- & -\end{aligned}$ & $\begin{aligned} P_{A}^{Y} & =0 \mathrm{~W} \\
P_{B}^{Y} & =0 \mathrm{~W} \\
P_{C}^{Y} & =0 \mathrm{~W} \\
P_{t o t}^{Y} & =0 \mathrm{~W} \\
P_{a v}^{Y} & =0 \mathrm{~W} \\
& -\end{aligned}$ & $\begin{array}{c}Q_{A}^{Y}=-53.59 \mathrm{var} \\
Q_{B}^{Y}=0 \mathrm{var} \\
Q_{C}^{Y}=-200 \mathrm{var} \\
Q_{t o t}^{Y}=-253.59 \mathrm{var} \\
Q_{a v}^{Y}=-84.53 \mathrm{var} \\
-\end{array}$ & $\begin{array}{c}\underline{I}_{A}^{Y}=(0+j 0) \mathrm{A} \\
\underline{I}_{A}^{Y}=0 \frac{/ 0^{\circ}}{\mathrm{A}} \\
\underline{I}_{B}^{Y}=(2.678-j 1.546) \mathrm{A} \\
\underline{I}_{B}^{Y}=3.093 \frac{/-30^{\circ}}{\mathrm{A}} \\
\underline{I}_{C}^{Y}=(-6.975-j 4.027) \mathrm{A} \\
\underline{I}_{C}^{Y}=8.055 \frac{/-150^{\circ}}{} \mathrm{A}\end{array}$ & $\begin{array}{c}\underline{I}_{Y}^{+}=(0+j 3.716) \mathrm{A} \\
\underline{I}_{Y}^{+}=3.716 \frac{190^{\circ}}{} \mathrm{A} \\
\underline{I}_{Y}^{-}=(1.432-j 1.858) \mathrm{A} \\
\underline{I}_{Y}^{-}=2.346 \frac{j-52.37^{\circ}}{} \mathrm{A} \\
\underline{I}_{Y}^{0}=(-1.432-j 1.858) \mathrm{A} \\
\underline{I}_{Y}^{0}=2.346 \frac{-127.63^{\circ}}{} \mathrm{A}\end{array}$ \\
\hline$\Delta$ & $\begin{aligned} C_{A B}^{\Delta}= & 33.93 u \mathrm{~F} \\
C_{B C}^{\Delta}= & 7.308 u \mathrm{~F} \\
C_{C A}^{\Delta}= & 0.653 u \mathrm{~F} \\
& - \\
& - \\
& -\end{aligned}$ & $\begin{array}{c}P_{A}^{\Delta}=-500 \mathrm{~W} \\
P_{B}^{\Delta}=400 \mathrm{~W} \\
P_{C}^{\Delta}=100 \mathrm{~W} \\
P_{t o t}^{\Delta}=0 \mathrm{~W} \\
P_{a v}^{\Delta}=0 \mathrm{~W} \\
-\end{array}$ & $\begin{array}{c}Q_{A}^{\Delta}=-900 \mathrm{var} \\
Q_{B}^{\Delta}=-1073.20 \mathrm{var} \\
Q_{C}^{\Delta}=-207.18 \mathrm{var} \\
Q_{t o t}^{\Delta}=-2180.38 \mathrm{var} \\
Q_{a v}^{\Delta}=-726,79 \mathrm{var} \\
-\end{array}$ & $\begin{array}{c}\underline{I}_{A}^{\Delta}=(-2.128+j 3.83) \mathrm{A} \\
{ }^{\Delta}{ }_{A}^{\Delta}=4.381 \frac{/ 119.05^{\circ}}{A} \mathrm{~A} \\
\underline{I}_{B}^{\Delta}=(3.104-j 3.758) \mathrm{A} \\
\underline{I}_{B}^{\Delta}=4.874 \frac{/-50.44^{\circ}}{} \mathrm{A} \\
\underline{I}_{C}^{\Delta}=(-0.976-j 0.072) \mathrm{A} \\
\underline{I}_{C}^{\Delta}=0.979 \frac{/-175.76^{\circ}}{} \mathrm{A}\end{array}$ & $\begin{array}{c}\underline{I}_{\Delta}^{+}=(0+j 3.093) \mathrm{A} \\
\underline{I}_{\Delta}^{+}=3.093 \frac{/ 90^{\circ}}{\mathrm{A}} \\
\underline{I}_{\Delta}^{-}=(-2.128+j 0.737) \mathrm{A} \\
\underline{I}_{\Delta}^{-}=2.252 / 160.89^{\circ} \mathrm{A} \\
\underline{I}_{\Delta}^{0}=(0+j 0) \mathrm{A} \\
\underline{I}_{\Delta}^{0}=0 \frac{/ 0^{\circ}}{} \mathrm{A}\end{array}$ \\
\hline
\end{tabular}

Table 4. Load-compensator assembly seen at source (in the PCC)—values valid for both compensators.

\begin{tabular}{|c|c|c|c|c|c|}
\hline Compo-nent & $\begin{array}{l}\text { Equivalent } \\
\text { Parameters }\end{array}$ & Real Powers & Reactive Powers & Phase Currents & Sequence Currents \\
\hline $\begin{array}{l}\text { Network } \\
\text { (PCC) }\end{array}$ & $\begin{aligned} R_{A}^{\text {net }}= & 61.361 \Omega \\
R_{B}^{\text {net }}= & 61.361 \Omega \\
R_{C}^{\text {net }}= & 61.361 \Omega \\
& - \\
& - \\
& -\end{aligned}$ & $\begin{array}{c}P_{A}^{\text {net }}=900 \mathrm{~W} \\
P_{B}^{\text {net }}=900 \mathrm{~W} \\
P_{C}^{\text {net }}=900 \mathrm{~W} \\
P_{\text {tot }}^{\text {net }}=2700 \mathrm{~W} \\
P_{a v}^{\text {net }}=900 \mathrm{~W} \\
-\end{array}$ & $\begin{aligned} Q_{A}^{\text {net }} & =0 \mathrm{var} \\
Q_{B}^{\text {net }} & =0 \mathrm{var} \\
Q_{C}^{\text {net }} & =0 \mathrm{var} \\
Q_{\text {tot }}^{\text {net }} & =0 \mathrm{var} \\
Q_{a v}^{\text {net }} & =0 \mathrm{var} \\
& -\end{aligned}$ & $\begin{array}{c}\underline{I}_{A}^{\text {net }}=(3.83+j 0) \mathrm{A} \\
\underline{I}_{A}^{\text {net }}=3.83 \frac{10^{\circ}}{} \mathrm{A} \\
\underline{I}_{B}^{\text {net }}=(-1.915-j 3.317) \mathrm{A} \\
\underline{I}_{B}^{\text {net }}=3.83 \frac{1-120^{\circ}}{} \mathrm{A} \\
\underline{I}_{C}^{\text {net }}=(-1.915+j 3.317) \mathrm{A} \\
\underline{I}_{C}^{\text {net }}=3.83 \frac{120^{\circ}}{} \mathrm{A}\end{array}$ & $\begin{array}{c}\underline{I}_{n e t}^{+}=(3.83+j 0) \mathrm{A} \\
\underline{I}_{n e t}^{+}=3.83 \frac{/ 0^{\circ}}{} \mathrm{A} \\
\underline{I}_{n e t}^{-}=(0-j 0) \mathrm{A} \\
\underline{I}_{n e t}^{-}=0 \underline{/ 0^{\circ}} \mathrm{A} \\
\underline{I}_{n e t}^{0}=(0+j 0) \mathrm{A} \\
\underline{I}_{n e t}^{0}=0 \frac{/ 0^{\circ}}{} \mathrm{A}\end{array}$ \\
\hline
\end{tabular}

The calculation was done by considering some usual simplifying conditions:

- The power supply network is considered an ideal one, providing a perfectly symmetrical and sinusoidal three-phase voltages set, so that the unbalance will occur only in currents.

- The circuit elements of type R, L, and C are considered ideal, perfectly linear.

- The impedances of the connections between the circuit elements or the impedance of the neutral conductor are not considered.

For the three-phase to neutral voltages, the rms value is considered $235 \mathrm{~V}$, the working frequency value is $50 \mathrm{~Hz}$ and the A phase to neutral voltage phasor is placed in the real axis of the complex plane. 
By applying the resizing method of the $\mathrm{Yn}$ and $\Delta$ compensators, the following values for the weighting factors (compensation levels) were obtained:

$$
k_{Y}^{+}=0.546, k_{\Delta}^{+}=0.454,\left(k_{Q}^{+}=k_{\Delta}^{+}+k_{Y}^{+}=1\right), k_{\Delta}^{-}=1, k_{Y, \Delta}^{0}=1
$$

From the analysis of the numerical calculation results, the following can be observed:

1. The Yn compensator acts exclusively on the reactive power flow on each phase, in both sizing versions. Containing only capacities, the $Y n$ compensator provides reactive power;

2. In the initial sizing variant, the Yn compensator provides the capacitive reactive power required to completely compensate the inductive reactive power of the load on the positive sequence, while in the resized variant, this function is shared with the $\Delta$ compensator; The Yn compensator acts only on the reactive power flow on each phase, in both sizing variants. Containing only capacities, the Yn compensator provides reactive power;

3. In the initial sizing variant, the $Y n$ compensator provides the capacitive reactive power required to completely compensate the inductive reactive power of the load on the positive sequence, while in the resized variant, this function is shared with the $\Delta$ compensator;

4. The $\Delta$ compensator resulted from the initial sizing (BRC), makes a redistribution of the active and reactive powers between the circuit phases, without changing their total on the three phases. It is also confirmed the sizing hypothesis according to which it acts only in the negative sequence currents flowing;

5. The $\Delta$ compensator in both versions contains only reactive passive elements, but also acts on the active power flow on the network phases: takes active power on the $B$ and $C$ phases and it delivers it back on the A phase. On the whole of the three phases the active power flow is not affected;

6. In both variants, the $\Delta$ compensator identically acts on the active power flow, which is the effect of the fact that it identically acts on the negative sequence currents flowing;

7. In both variants, the compensator assembly $(\mathrm{Yn}+\Delta)$ has the same effect: completely compensates the five undesired components of the load sequence currents.

The results of the Mathcad calculation were confirmed by building a model of the same three-phase circuits using the Matlab-Simulink tool, the SimPowerSys module. Virtual measuring instruments have been installed to "measure" the same electrical amounts, to which virtual oscilloscopes have been added for voltages and currents waveforms viewing. In normal steady-state operating conditions, the measurement virtual instruments have indicated the same values of powers and currents as those obtained through the Mathcad calculation. Figures 4 and 5, respectively, show the Matlab models for BRC and BCC. Figure 6a-h shows the waveforms obtained by the virtual oscilloscopes installed, for both sizing cases, in the five sections considered significant, i.e., the terminals of the load, $\mathrm{Yn}$ compensator, $\Delta$ compensator, $\mathrm{Yn}+\Delta$ compensator and load-compensator assembly (in the PCC).

Matlab modeling confirms all the conclusions deduced above and additionally allows viewing the effect of the action of the two compensator components in the three-phase currents waveforms in the PCC (Figure 6h). The balancing of the currents is perfect, and their time sequence is positive. Reducing the amplitude of the currents is the effect of positive sequence currents compensation. Overlapping the current and voltage waveforms shows zero phase shifts between current and phase to neutral voltage on each phase, demonstrating the active nature of currents and powers in the PCC. 


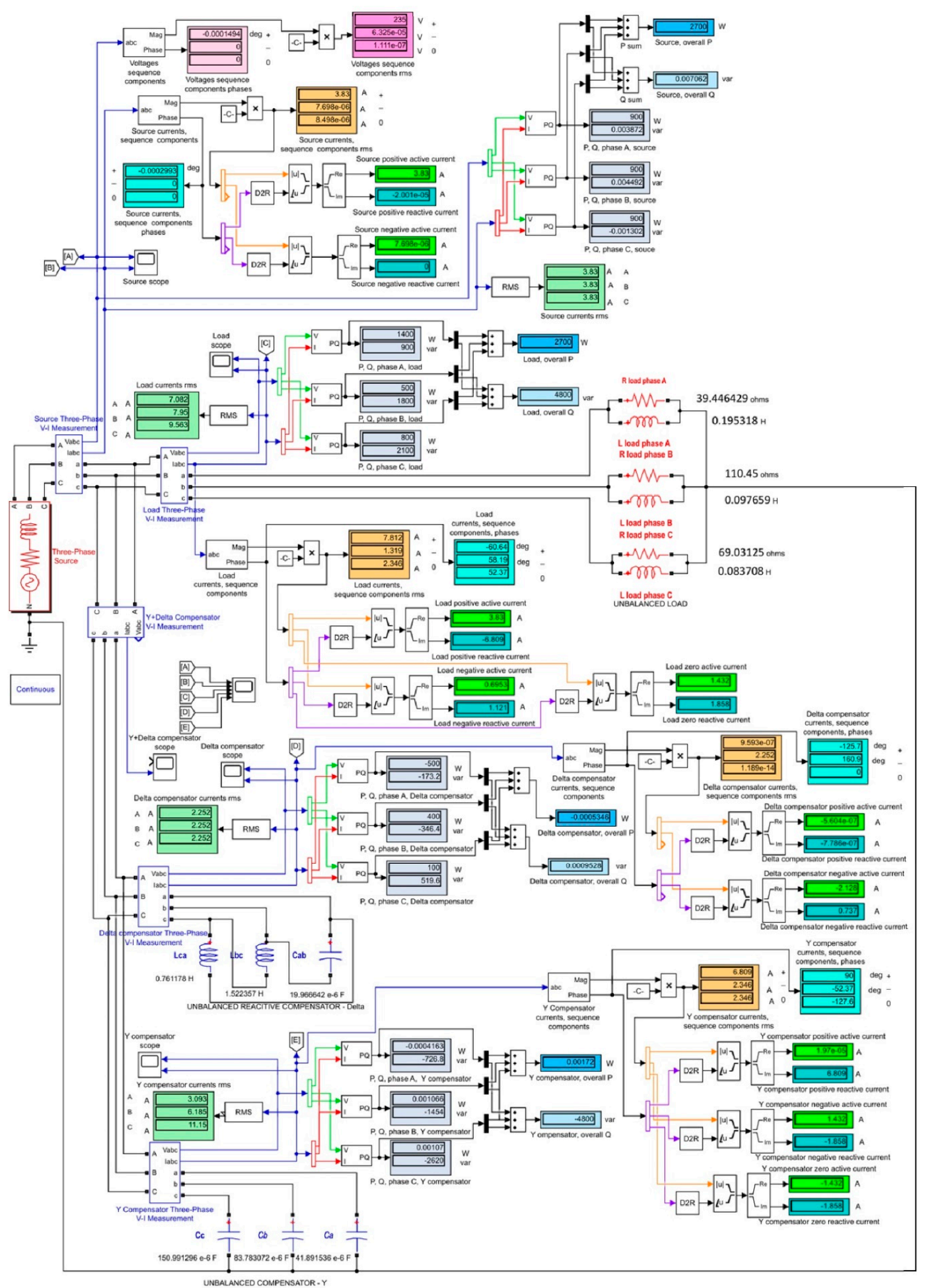

Figure 4. The Matlab model used to study the BRC operation considered in the case study. 


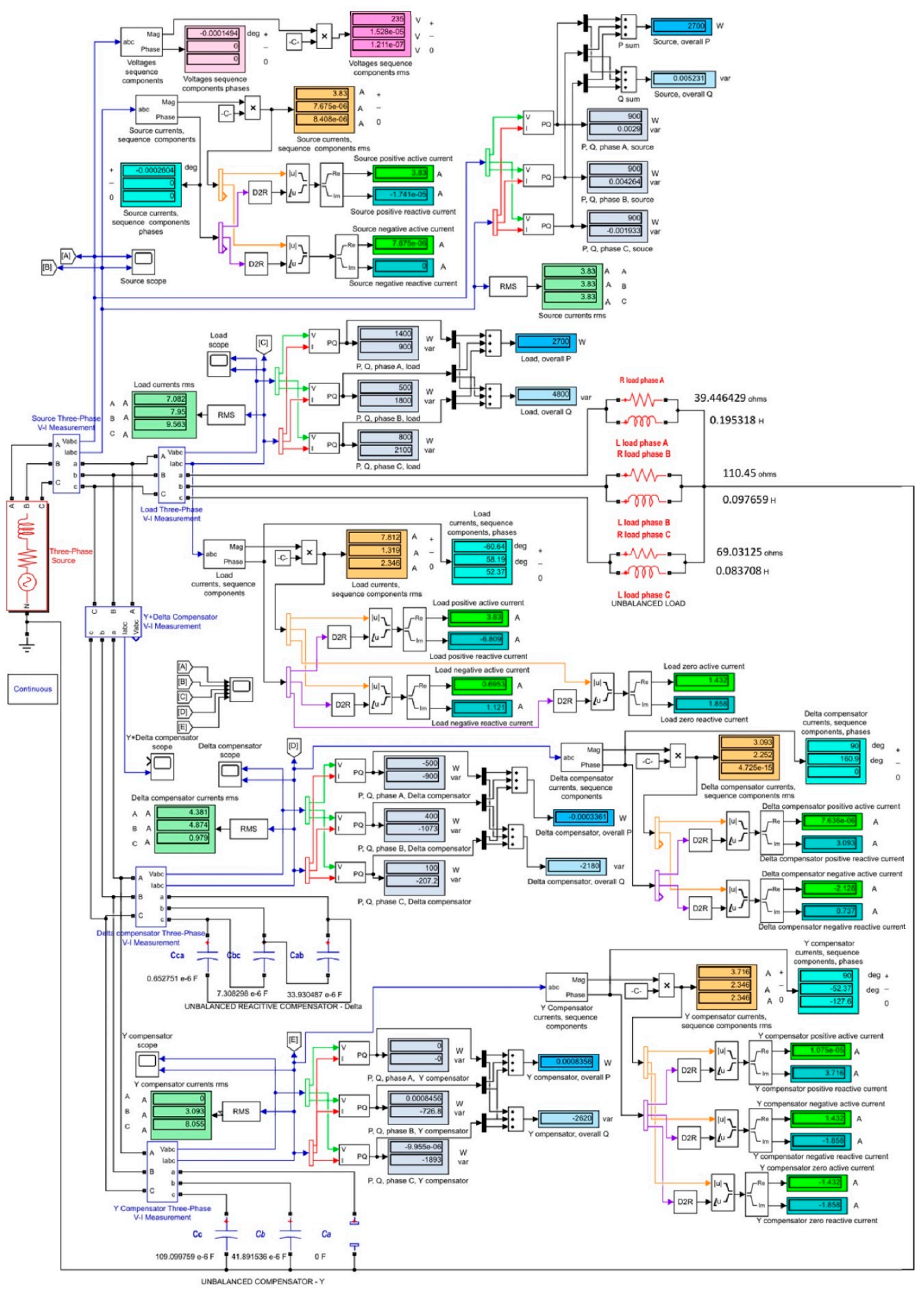

Figure 5. The Matlab model used to study the BCC operation considered in the case study. 

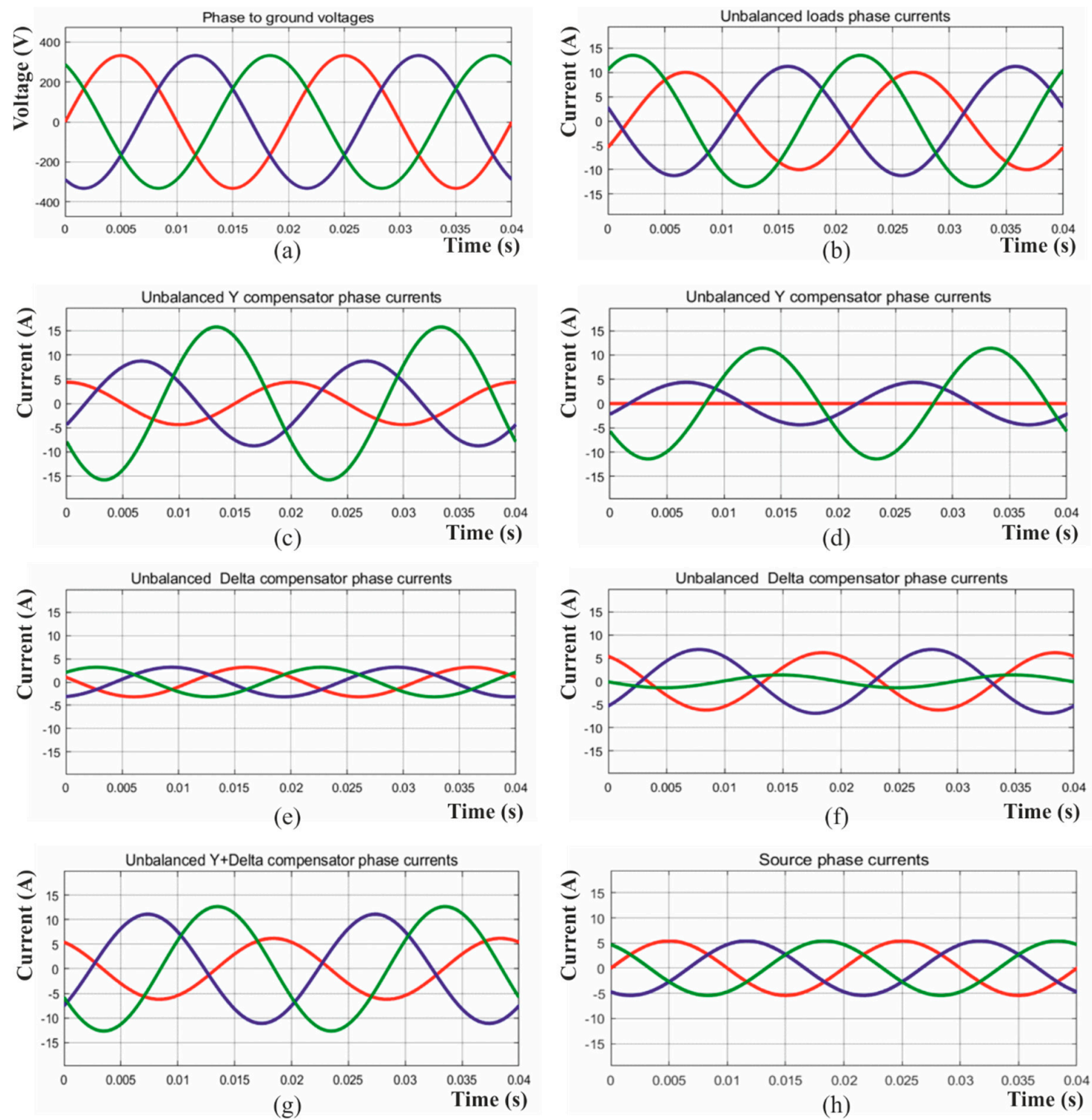

- phase A

- phase B

- phase C

Figure 6. Voltages and currents waveforms in the sections of the load-compensator assembly: (a) phase to neutral voltages (BRC and BCC); (b) currents on the load phases (BRC and BCC); (c) currents on the Yn compensator phases (BRC); (d) currents on the Yn compensator phases (BCC); (e) currents on the $\Delta$ compensator (BRC) phases; (f) currents on the $\Delta$ compensator phases (BCC); (g) currents on the $\mathrm{Yn}+$ $\Delta$ compensators phases (BRC and BCC); and (h) currents on the phases in PCC (BRC and BCC).

The results of this case study demonstrate that the compensation of the inductive reactive power and total balancing of the loads can be obtained by unbalanced capacitive compensation, using a SVC type BCC.

\section{Conclusions}

Currently, an accelerated development of SPC solutions for the electrical equipment type CPD used for power quality improving in the PCC can be seen. The authors of this article consider that compensators such as SVCs remain valid for many applications intended for consumers or distribution system operators. It is for those applications that the criterion of installation and operation costs is more important than the criterion regarding the speed reaction or control accuracy. 
The paper briefly presents a mathematical model for sizing a BRC for a three-phase four-wire network and then an iterative method for resizing it to transform it into a BCC.

The resizing method can be implemented in the form of an iterative algorithm in the control system of an ABCC, which has the main advantage that the compensation level can be individually controlled for each component load sequence current (positive, negative and zero). This allows the optimal control of the capacitive reactive power distribution between the two compensator functions: PF improving and load balancing.

The paper contains the results of a case study that analyzed the powers and currents flow on the phases of the load-compensator assembly, for both compensator sizing versions. These results validate the mathematical model and demonstrate the possibility of completely compensation of the reactive power on the positive sequence and the completely balancing of three-phase loads in four-wire networks, by unbalanced capacitive compensation.

An SVC type ABCC that commands individually the switching of single-phase capacitor banks steps becomes a very advantageous solution for many applications of industrial or commercial customers, both by lowering costs due to the removal of high-power coils and by simplifying the automatic system of compensation.

Author Contributions: Conceptualization, Methodology, Validation: A.P.; Investigation: A.P., A.B., and F.M.-M.; Writing-Original Draft Preparation: A.P.; and Writing-Review and Editing: A.B. and F.M.-M.

Funding: This research received no external funding.

Conflicts of Interest: The authors declare no conflict of interest.

\section{Abbreviations and Notations}

\begin{tabular}{|c|c|}
\hline PCC & Point of Common Coupling \\
\hline $\mathrm{RPC}$ & Reactive Power Compensator \\
\hline SVC & Static var Compensator \\
\hline $\mathrm{ABC}$ & Adaptive Balancing Compensator \\
\hline $\mathrm{ABCC}$ & Adaptive Balancing Capacitive Compensator \\
\hline $\mathrm{BRC}$ & Balancing Reactive Compensator \\
\hline $\mathrm{BCC}$ & Balancing Capacitive Compensator \\
\hline SPC & Switching Power Converter \\
\hline TCR & Thyristor Controlled Reactor \\
\hline TSC & Thyristor Switched Capacitor \\
\hline CSC & Contactor Switched Capacitor \\
\hline IGBT & Insulated Gate Bipolar Transistor \\
\hline IGCT & Integrated Gate Commutated Thyristor \\
\hline SSD & Solid State Device \\
\hline CPD & Custom Power Device \\
\hline D-STATCOM & Distribution Static Synchronous Compensator \\
\hline DVR & Dynamic Voltage Restorer \\
\hline UPQC & Unified Power Quality Conditioner \\
\hline VSI & Voltage Source Inverter \\
\hline TSSPC & Thyristor Switched Single Phase Capacitor \\
\hline CSSPC & Contactor Switched Single Phase Capacitor \\
\hline$\underline{I}_{n e t}^{+}, \underline{I}_{n e t}^{-}, \underline{I}_{n e t}^{0}$ & $\begin{array}{l}\text { phasors of symmetrical components of the phase currents at the } \\
\text { network (in PCC) }\end{array}$ \\
\hline$\underline{I}_{\text {load }}^{+} \underline{I}_{\text {load }}^{-} \underline{I}_{\text {load }}^{0}$ & phasors of symmetrical components of the phase currents at the load \\
\hline$\underline{I}_{Y}^{+}, \underline{I}_{Y}^{-}, \underline{I}_{Y}^{0}$ & $\begin{array}{l}\text { phasors of symmetrical components of the phase currents at Yn } \\
\text { compensator }\end{array}$ \\
\hline$\underline{I}_{A}^{Y}, \underline{I}_{B}^{Y}, \underline{I}_{C}^{Y}$ & phasors of the phase currents at Yn compensator \\
\hline$I_{A}^{Y}, I_{B}^{Y}, I_{C}^{Y}$ & rms values of the compensation currents at $Y \mathrm{n}$ compensator \\
\hline$\underline{\mathrm{I}}_{\Delta}^{+}, \underline{\mathrm{I}}_{\Delta}^{-}, \underline{\mathrm{I}}_{\Delta}^{0}$ & $\begin{array}{l}\text { phasors of symmetrical components of the phase currents at } \Delta \\
\text { compensator }\end{array}$ \\
\hline$\underline{I}_{A}^{\Delta}, \underline{I}_{B}^{\Delta}, \underline{I}_{C}^{\Delta}$ & phasors of the phase currents at $\Delta$ compensator \\
\hline$\underline{I}_{A B^{\prime}}^{\Delta} \underline{I}_{B C}^{\Delta}, \underline{I}_{C A}^{\Delta}$ & phasors of the currents on $\Delta$ compensator branches \\
\hline
\end{tabular}




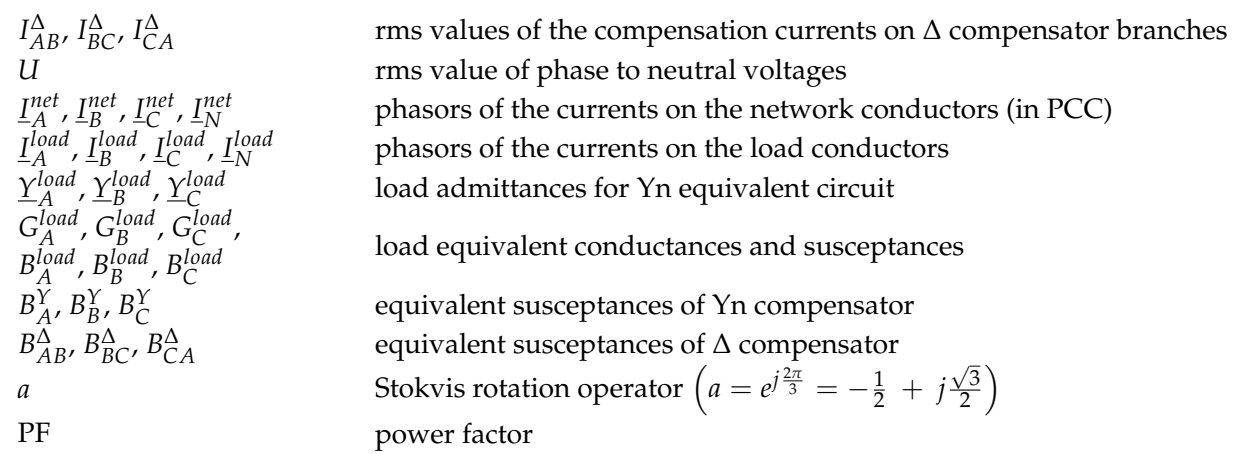

\section{References}

1. Dugan, R.C.; McGranaghan, M.F.; Beaty, H.W. Electric Power Systems Quality, 2nd ed.; McGraw-Hill Education: New York, NY, USA, 2006; ISBN 978-0071386227.

2. Antonio, M.M. Power Quality: Mitigation Technologies in a Distributed Environment; Springer: London, UK, 2007; ISBN 978-1-84628-772-5.

3. Ewald, F.F.; Mohammad, A.S.M. Power Quality in Power Systems and Electrical Machines; Elsevier Academic Press: London, UK, 2008; ISBN 978-0-08-055917-9.

4. Steinmetz, C.P. Theory and Calculation of Electrical Apparatus; McGraw Hill Book Company: New York, NY, USA, 1917.

5. Grandpierr, M.; Trannoy, B. A stationary power device to rebalance and compensate reactive power in three-phase network. In Proceedings of the 1977 IAS Annual Conference, Los Angeles, CA, USA, 2-6 October 1977; pp. 127-135.

6. Gyugyi, L.; Otto, R.; Putman, T. Principles and applications of static thyristor-controlled shunt compensators. IEEE Trans. Power Appl. Syst. 1935, PAS-97, 1935-1945. [CrossRef]

7. Miller, J.E. Reactive Power Control in Electric Systems; John Wiley \& Sons: New York, NY, USA, 1982.

8. Gueth, G.; Enstedt, P.; Rey, A.; Menzies, R.W. Individual phase control of a static compensator for load compensation and voltage balancing. IEEE Power Eng. Rev. 1987, 2, 898-905. [CrossRef]

9. Czarnecki, L.S. Reactive and unbalanced currents compensation in three-phase asymmetrical circuits under nonsinusoidal conditions. IEEE Trans. Instrum. Meas. 1989, 38, 754-759. [CrossRef]

10. Czarnecki, L.S. Minimization of unbalanced currents in three-phase asymmetrical circuits with nonsinusoidal voltage. IEE Proc. B Electr. Power Appl. 1992, 139, 347-354. [CrossRef]

11. Lee, S.Y.; $\mathrm{Wu}, \mathrm{C}$.J. On-line reactive power compensation schemes for unbalanced three-phase four wire distribution systems. IEEE Trans. Power Deliv. 1993, 8, 1235-1239. [CrossRef]

12. Czarnecki, L.S. Supply and loading quality improvement in sinusoidal power systems with unbalanced loads supplied with asymmetrical voltage. Arch. Elektrotech. 1994, 77, 169-177. [CrossRef]

13. Czarnecki, L.S.; Hsu, S.M. Thyristor controlled susceptances for balancing compensators operated under nonsinusoidal conditions. IEE Proc. Electr. Power Appl. 1994, 141, 177-185. [CrossRef]

14. Czarnecki, L.S.; Hsu, S.M.; Chen, G. Adaptive balancing compensator. IEEE Trans. Power Deliv. 1995, 10, 1663-1669. [CrossRef]

15. Oriega de Oliveira, L.C.; Barros Neto, M.C.; de Souza, J.B. Load compensation in four-wire electrical power systems. In Proceedings of the International Conference on Power System Technology, Perth, WA, Australia, 4-7 December 2000; pp. 1575-1580.

16. Arendse, C.; Atkinson-Hope, G. Design of a Steinmetz Symmetrizer and application in unbalanced network. In Proceedings of the 45th International Universities Power Engineering Conference (UPEC2010), Cardiff, UK, 31 August-3 September 2010; pp. 1-6.

17. Lee, S.-Y.; Wu, C.-J.; Chang, W.-N. A compact control algorithm for reactive power compensation and load balancing with static var compensator. Electr. Power Syst. Res. 2001, 58, 63-70. [CrossRef]

18. Mayordomo, J.G.; Izzeddine, M.; Asensi, R. Load and voltage balancing in harmonic power flows by means of static var compensators. IEEE Trans. Power Deliv. 2002, 17, 761-769. [CrossRef]

19. Grünbaum, L.; Petersson, A.; Thorvaldsson, B. FACTS improving the performance of electrical grids. In $A B B$ Review (Special Report on Power Technologies); ABB Group: Zürich, Switzerland, 2003; pp. 13-18. 
20. Dixon, J.; Morán, L.; Rodríguez, J.; Domke, R. Reactive power compensation technologies, state of-the-art review. Proc. IEEE 2005, 93, 2144-2164. [CrossRef]

21. Quintela, F.R.; Arevalo, J.M.G.; Redondo, R.C. Power analysis of static var compensators. Int. J. Electr. Power Energy Syst. 2008, 30, 376-382. [CrossRef]

22. Said, I.K.; Pirouti, M. Neural network-based load balancing and reactive power control by static var compensator. Int. J. Comput. Electr. Eng. 2009, 1, 25-31. [CrossRef]

23. Xu, Y.; Tolbert, L.M.; Kueck, J.D.; Rizy, D.T. Voltage and current unbalance compensation using a static var compensator. IET Power Electr. 2010, 3, 977-988. [CrossRef]

24. Jeon, S.-J.; Willens, J.L. Reactive power compensation in multi-line systems under sinusoidal unbalanced conditions. Int. J. Circuit Theory Appl. 2011, 39, 211-224. [CrossRef]

25. Pană, A.; Băloi, A.; Molnar-Matei, F. Experimental validation of power mechanism for load balancing using variable susceptances in three-phase four-wire distribution networks. In Proceedings of the International Conference on "Computer as a Tool"-EUROCON 2007, Warsaw, Poland, 9-12 September 2007; pp. 1567-1572.

26. Pană, A.; Băloi, A.; Molnar-Matei, F. Load balancing by unbalanced capacitive shunt compensation-A numerical approach. In Proceedings of the 14th International Conference on Harmonics and Quality of Power-ICHQP 2010, Bergamo, Italy, 26-29 September 2010; pp. 1-6.

27. Pană, A. Active load balancing in a three-phase network by reactive power compensation. In Power Quality -Monitoring, Analysis and Enhancement; Zobaa, A., Ed.; InTech: Rijeka, Croatia, 2011; pp. 219-254.

28. Sun, Q.; Zhou, J.; Liu, X.; Yang, J. A novel load-balancing method and device by intelligent grouping compound switches-based capacitor banks shunt compensation. Math. Probl. Eng. 2013, 2013, 11. [CrossRef]

29. Hingorani, N.G.; Gyugyi, L. Understanding FACTS: Concepts and Technology of Flexible AC Transmission Systems; Wiley: Hoboken, NJ, USA, 2000.

30. Lee, S.-Y.; Wu, C.-J. Reactive power compensation and load balancing for unbalanced three-phase four-wire system by a combined system of an svc and a series active filter. IEE Proc. Electr. Power Appl. 2000, 147, 563-578. [CrossRef]

31. Haque, M.H. Compensation of distribution system voltage sag by DVR and DSTATCOM. In Proceedings of the IEEE Porto Power Tech Proceedings, Porto, Portugal, 10-13 September 2001; pp. 10-13.

32. Wang, B.; Cathey, J.J. DSP-Controlled, Space-Vector PWM, Current Source Converter for STATCOM application. Electr. Power Syst. Res. 2003, 67, 123-131. [CrossRef]

33. Dixon, J.; del Valle, Y.; Orchard, M.; Ortuzar, M.; Moran, L.; Maffrand, C. A full compensating system for general loads, based on a combination of thyristor binary compensator, and a PWM-IGBT active power filter. IEEE Trans. Ind. Electron. 2003, 50, 982-989. [CrossRef]

34. Nguyen, P.T.; Saha, T.K. Dynamic voltage restorer against balanced and unbalanced voltage sags: Modeling and simulation. In Proceedings of the Power Engineering Society General Meeting, Denver, CO, USA, 6-10 June 2004; Volume 2.

35. Nielsen, J.G.; Newman, M.; Nielsen, H.; Blaabjerg, F. Control and testing of a dynamic voltage restorer (DVR) at medium voltage level. IEEE Trans. Power Electron. 2004, 3, 806-813. [CrossRef]

36. Mienski, R.; Pawelek, R.; Wasiak, I. Shunt compensation for power quality improvement using a STATCOM controller: Modeling and simulation. IEE Proc. Gener. Transm. Distrib. 2004, 274-280. [CrossRef]

37. Pakdel, M.; Farzaneh-Fard, H. A control strategy for load balancing and power factor correction in three-phase four-wire systems using a shunt active power filter. In Proceedings of the IEEE International Conference on Industrial Technology (ICIT 2006), Mumbai, India, 15-17 December 2006; pp. 579-584.

38. Akagi, H.; Fujita, H.; Yonetani, S.; Kondo, Y. A 6.6-kV transformerless STATCOM based on a five-level diode-clamped PWM converter: System design and experimentation of a 200-V, 10-kVA laboratory model. IEEE Trans. Ind. Appl. 2008, 44, 672-680. [CrossRef]

39. Singh, B.N.; Saha, R.; Chandra, A.; Al-Haddad, K. Static synchronous compensators (STATCOM): A review. IET Power Electron. 2009, 2, 297-324. [CrossRef]

40. Mishra, M.K.; Karthikeyan, K. An investigation on design and switching dynamics of a voltage source inverter to compensate unbalanced and nonlinear loads. IEEE Trans. Ind. Electron. 2009, 56, 2802-2810. [CrossRef]

41. Lee, W.C.; Lee, D.M.; Lee, T.K. New control scheme for a unified power-quality compensator-q with minimum active power injection 2010. IEEE Trans. Power Deliv. 2010, 25, 1068-1076. [CrossRef] 
42. Capitanescu, F.; Wehenkel, L. Redispatching active and reactive powers using a limited number of control actions. IEEE Trans. Power Syst. 2011, 26, 1221-1230. [CrossRef]

43. Win, T.S.; Hiraki, E.; Okamoto, M.; Lee, S.R.; Tanaka, T. Constant DC capacitor voltage control based strategy for active load balancer in three-phase four-wire distribution system. In Proceedings of the 2013 International Conference on Electrical Machines and Systems (ICEMS), Busan, Korea, 26-29 October 2013; pp. 1560-1565.

44. Fu, X.; Chen, H.; Mo, W. Dynamic voltage restorer based on active hybrid energy storage system. In Proceedings of the 2014 IEEE PES Asia-Pacific Power and Energy Engineering Conference (APPEEC), Hong Kong, China, 7-10 December 2014; pp. 1-4.

45. Hingorani, N.G. Introducing custom power. IEEE Spectr. 1995, 32, 41-48. [CrossRef]

46. Ghosh, A. Power Quality Enhancement Using Custom Power Devices; Springer: New York, NY, USA, 2002; ISBN 978-1-4020-7180-5.

47. Crow, M.L. Power quality enhancement using custom power devices. IEEE Power Energy Mag. 2004, 2, 50. [CrossRef]

48. Domijan, A., Jr.; Montenegro, A.; Kern, A.J.F.; Mattern, K.E. Custom power devices: An interaction study. IEEE Trans. Power Syst. 2005, 20, 1111-1118. [CrossRef]

49. Gupt, S.; Dixit, A.; Mishra, N.; Singh, S.P. Custom power devices for power quality improvement: A review. Int. J. Res. Eng. Appl. Sci. 2012, 2, 1646-1659.

50. Roncero-Sànchez, P.; Acha, E. Design of a control scheme for distribution static synchronous compensators with power-quality improvement capability. Energies 2014, 7, 2476-2497. [CrossRef]

51. Hosseinzadeh, M.; Salmasi, F.R. Robust optimal power management system for a hybrid AC/DC micro-grid. IEEE Trans. Sustain. Energy 2015, 6, 675-687. [CrossRef]

52. Farkoush, S.G.; Kim, C.-H.; Rhee, S.-B. THD reduction of distribution system based on ASRFC and HVC method for SVC under EV charger condition for power factor improvement. Symmetry 2016, 8, 156. [CrossRef]

53. Tokiwa, A.; Yamada, H.; Tanaka, T.; Watanabe, M.; Shirai, M.; Teranishi, Y. New hybrid static var compensator with series active filter. Energies 2017, 10, 1617. [CrossRef]

54. Xue, Y.; Zhang, X.P. Reactive power and AC voltage control of LCC HVDC system with controllable capacitors 2017. IEEE Trans. Power Syst. 2017, 32, 753-764. [CrossRef]

55. Barrios-Martínez, E.; Ángeles-Camacho, C. Technical comparison of FACTS controllers in parallel connection. J. Appl. Res. Technol. 2017, 15, 36-44. [CrossRef]

56. Pana, A.; Baloi, A.; Molnar-Matei, F. From the Balancing Reactive Compensator to the Balancing Capacitive Compensator. Energies 2018, 11, 1979. [CrossRef] 